\title{
A Persisting Wound: Charles Dumas' 9/11 - A Day in the Life of A People
}

\author{
Nehal Ahmad Muhammad Maklad
}

\section{Introduction:}

This paper intends to explore the possibility of representing the traumatic experience of 9/11 $1^{\text {th }}$ attacks in Charles Dumas' 9/11 - A Day in the Life of A People (2008), within the theoretical framework of literary trauma theory in its pluralistic model. By tracing evidence for the possibility of representing this experience in this play, it tries to defy the common belief held by the classic model of this theory about the unrepresentability of trauma and show that psychic wounds are, sometimes, worse than physical ones. It also discusses the impact of the traumatic experience of the attacks of $9 / 11^{\text {th }}$ on twelve ordinary Americans before, during, a year after, and seven years later on the American people. The traumatic experience presented in the play under-study is traced starting from the point of what may seem to be unspeakable or unrepresentable to the points of full representation, and it is eventually claimed and understood through a social and/or political context.

One of the turning points in the history of the United States of America and perhaps in the history of the entire globe - is the attacks of September $11^{\text {th }} 2001$. As the CBC News reported on that day, these attacks were committed by four commercial passenger jet airliners, two of which have crashed into the Twin Towers of the World Trade Center of Manhattan, New York, a third into the Pentagon in Arlington, Virginia, just outside Washington, D.C. and a fourth that crashed into a field in rural Pennsylvania after some of its passengers and flight crew attempted to retake control of it in 2001 (par. 7). Crashing into the hearts and minds of the American people along with these places, these attacks deserve Kristiaan Versluys' description in his essay 9/11 as a European Event 2007 in which he calls them "the defining tragedy of our time" (65). In addition to 2,995 dead people (Alfano par. 2), these attacks left behind great consequences that befell not only those who died, but even worse, those who survived. One of the survivors wonders bitterly when asked about the influence the attacks left behind on his life:

Am I affected? Yeah. I'm dealing with a lot of survivor's guilt. The sadness is there. I try to be funny and I think I'm moderately successful, but it happens probably a couple times a day that I think about Sept. 11, and how things have changed so much. (Otten par. 4)

One of the greatest afflictions these attacks resulted in was the huge number of people who suffered emotionally or psychologically after them. Most of those people demonstrated a number of symptoms that distinguish a psychological disorder known as PTSD (i.e. Post-Traumatic Stress Disorder) which affects people's relation to self and society. The Diagnostic and Statistical Manual of Mental Disorders provides a number of symptoms that characterize PTSD: "a person who is traumatized will re-experience such events as 'recurrent and intrusive distressing recollections of the event, including images, thoughts, or perceptions', 
that may take the form of memories, dreams, flashbacks, hallucinations, recurrences, and/or dissociation" (qtd. in Walker 106).

Unfortunately, PTSD befell many American citizens though most of them were not inside, or even close to, these buildings. Catherine Ann Collins and Jeanne Ellen Clark justify the prevalence of this high percentage of PTSD among the American people in their "Introduction: Addressing the Unspeakable" that opens their book Speaking the Unspeakable 2013 explaining that,

Having watched the plane crash into the second tower live on television could prove traumatic whether one was watching from New York, California, or London. The public may be absent from the place of the trauma, but if they are present at the time of the trauma it allows one to become a remote participant, potentially 'transformed' by their participation (Collin and Clark xiv).

On September $11^{\text {th }}, 2001$, the American playwright, director, actor and Associate Theatre Professor at Penn State University Charles Dumas (1947- ) was in New York filming a television show and like many Americans, he was deeply affected by the attacks on the World Trade Center. A year later, when he was on a Fulbright Fellowship in the Republic of South Africa, he realized that people in Africa did not fully understand the effect the attacks had on ordinary Americans including him.

Therefore, Dumas decided to write a based-on-stories-from-real-folk play which became 9/11 - A Day in the Life of A People, first introduced in 2002 and completed in 2008. However, that was not the only reason that made Dumas write this play and introduce it to the public. In addition to telling others about the impact of the attacks on ordinary Americans, Dumas illustrates in one of his interviews that he wanted the American people to remember "who they were, who they are, and who they are to become" (Elser par. 13). He also adds that he wanted to help people heal by remembering. He said: "People want to tell what their experience was, the point of it is to revisit and open up the wounds that need to be opened again so we can begin to heal better" (par. 14).

Dumas' play has found its match in literary trauma theory. Literary trauma theory is concerned with the possibility of representing or claiming a traumatic experience within a literary work. It is represented by two groups of critics. On one hand, there is the classic model of the theory whose representatives believe in the unrepresentability of traumatic experiences because of certain pathologic characteristics that distinguish psychological trauma, among which is dissociation that causes the unspeakability or loss of this experience. Cathy Caruth (1955- ), a pioneering figure of this model states: "Trauma is not locatable in the simple violent or original event in an individual's past, but rather in the way that its very unassimilated nature - the way it was precisely not known in the first instance returns to haunt the survivor later on" (Caruth Unclaimed Experience 4). On the other hand, there is the newly emerging model of the theory labeled as the 'pluralistic model' whose many critics believed in the possibility of representing and 
claiming traumatic experiences. One of the suggestions provided by this group of critics was believing that the traumatic experience could be claimed or understood within certain social and/or political contexts. This group also believed that dissociation, which is said to cause the loss of the experience, was not the only symptom of trauma and that trauma has other symptoms that allow for claiming an experience. Michelle Balaev (1974 - ), a contemporary prominent figure of this model, explains: "the values attributed to the traumatic experience are largely shaped by cultural forces created within the world of the novel [or any literary work]" (Balaev, "Trends in Literary Trauma Theory" par. 12).

It is, thus, in this respect that the paper mainly focuses on literary trauma theory and argues in line with the critics of the pluralistic model of the theory that believes in the representability or speakability of a traumatic experience. It applies the main notions provided by this model to Charles Dumas' 9/11 - A Day in the Life of A People, in an attempt to trace and analyze the traumatic experience presented in it. The choice of this play intends to answer the following research questions: (1) how can certain traumatic experiences that may seem folded with silence be claimed in literary works? (2) Are the aspects of a traumatic experience bond to the difficult situations a person goes through or do they have other factors that may proceed or follow this experience? (3)What are some of the social-political contexts within which traumatic experiences can be understood? (4) How can the technique of a literary work echo a traumatic experience? 


\section{A Persisting Wound: Charles Dumas' 9/11 - A Day in the Life of A People:}

Charles Dumas' 9/11 A Day in the Life of A People 2008 is a contemporary American play that opens new possibilities for the 'representation' or 'speakability' of a traumatic event that has been considered by many scholars and critics unrepresentable. This event is the attacks of September $11^{\text {th }} 2001$ in the United States of America. Although these attacks affected different aspects of the American life including the economic, political, military ...etc., they left behind great emotional and psychological afflictions. According to a research published by the Journal of Traumatic Stress in 2011, "these attacks resulted in a wave of stress and anxiety across the United States causing almost 40 percent of Americans to experience symptoms consistent with PTSD," besides those approximately 2,995 killed people (Wiley-Blackwell par. 1). On the literary level, while writers tried to reflect the effects of these attacks, many critics believed in their unrepresentability due to the traumatic nature they enjoyed.

In her book Frames of Memory after 9/11 2015, Lucy Bond provided a number of examples for critics who embrace the idea of the unrepresentability of the traumatic experience of September 11 ${ }^{\text {th }}$. V. S. Naipaul, for instance, argues that the attacks were "too astonishing" to the extent that "only nonfiction could capture the complexities of today's world" (Bond 26). James Berger believes that "[n]othing adequate, nothing corresponding in language could stand in for it. No metaphor could carry language across to it" (26). These critics have certainly established their claims on the fact that many of the literary works presented after September $11^{\text {th }}$ were dominated by "the notion of rupture" (23). However, it is possible that these works only needed a frame of work to interpret them through or a context to place them in (23). In their article "Representing 9/11: Literature and Resistance" that introduces their book Literature after 9/11 2008, Ann Keniston and Jeanne Follansbee Quinn argue that the literature written after September $11^{\text {th }}$ needs a "culture-wide" value for interpreting it. This 'culture' value is meant to replace or "refuse" the feeling of the unrepresentability or "incommensurability" of the experience of 9/11 with something that places it into a "framework". Keniston and Quinn say:

While the initial experience of 9/11 seemed unprecedented and cataclysmic, the experience of incommensurability generated a culturewide need for explanatory narratives, not simply as a means for countering the trauma, but as a means for refusing incommensurability, prompting attempts to place 9/11 into an historical framework (3).

Keniston's and Quinn's idea of a "framework" necessitated by a "culture-wide need for explanatory narrative" suggests the importance of interpreting September $11^{\text {th }}$ within certain context. This context could be a social or a political one that would allow for better understanding of such traumatic experience. Laurie Vickroy states that, "Examining how cultural values influence traumatic experience is essential to understanding trauma's aftermath" (130). 
In this light, Dumas's play allows for representing the traumatic event of September $11^{\text {th }}$ by placing it within a social and political context that provides a deeper understanding of this experience. It also proves the invalidity of some of the basic conventions of the classic model of trauma theory that refuses the possibility of representing trauma since its main feature is dissociation. Tracing the lives of twelve ordinary Americans on the morning of the attacks, a year later, and seven years after, Dumas' play manages to represent the traumatic experience of September $11^{\text {th }}$ as a severe overwhelming event that left behind devastating effects and that was elevated from the individual to the collective level. Furthermore, the representability of September $11^{\text {th }}$ as allowed for in this play is supported by a unique literary aspect it enjoys. Not only does this play introduce September $11^{\text {th }}$ as a representable traumatic experience in the core of its content or major theme, but it also represents it in the very integration between this theme and the literary techniques it employs, including its structure, plot, characters, setting, language, ... etc.

9/11 A Day in the Life of A People was first read as one-act play on the first anniversary of the attacks in 2002. With the addition of an entire second act -written six years after the first one, the entire play premiered in 2008 at the Philadelphia Fringe Festival. Each act of the play represents a stage or an aspect of the traumatic experience in its very general sense as agreed upon by both psychologists and literary scholars: "an event in the subject's life defined by its intensity, by the subject's incapacity to respond adequately to it, and by the upheaval and longlasting effects that it brings about in the psychical organization" (qtd. in Wald). The first act represents the stage of the event or the experience as remembered by the characters only a year after the attacks. The second one represents the effect or the response stage as traced through the change in the characters' actions and attitudes seven years after the attacks.

On one hand, the first act represents the 'acting out' stage or the compulsive repetition of the event as it returns a year after the attacks. However, it is not a mere acting out or meaningless repetition of the event; it implies certain facts about the attacks that emphasize their representability since the very beginning of their occurrence. Although it appears, like the rest of the literature written immediately after the attacks, structurally weak or has a narrative void, which classic critics of trauma theory would have attributed to the unspeakability of the event, this act can be read in light of Balaev's and Vickroy's idea of a social and political context. The characters' memories in this act demonstrate that the severity of this experience is not just limited to the difficult situations some individuals had to go through on that day but extends to some implications resulting from the attacks.

On the other hand, the second act represents the 'working through' stage through which characters demonstrate more or deeper understanding of the nature of their experience, though not necessary overcome it. This act stresses the effect resulting from this traumatic experience on the same- even-deeper levels suggested by Balaev: psychological, social, and political. On the psychological level, it demonstrates a number of PTSD symptoms that can be traced through the characters 
seven years after the attacks. So, one can understand the change in the characters' actions and attitudes in this act, as well. Also, this act asserts the merge between the individual and the collective experiences of September $11^{\text {th }}$ within the social political context. It shows how the continued manipulation of the American government seven years after the attacks helped afflict the identity of the entire society not merely those of some individuals.

Besides these thematic aspects, each act enjoys a unique structure and follows different techniques. The first act is divided into parts: before, during, and a year after the attacks. It is a presentational act in which twelve characters address the audience directly on a bare stage but from some slides. Characters' stories in this act are unconnected following no certain order and coming in the form of snapshots. The second act, on the contrary, is divided into scenes not parts. The stage becomes bare no more as each scene has its own setting in this act. Also, characters interact dramatically and the play's plot becomes more linear. As the value of a literary work is decided by both its form and content, the integration between the thematic features and the structural and technical ones in this play are of great value to the representation of this traumatic experience within a literary frame of work.

Act I of this play addresses the intensity or severity of September $11^{\text {th }}$ experience as people still remember it a year after the attacks. So, what severe memories about the intense event of September $11^{\text {th }}$ do characters' stories bear witness for in this act? The answer to this question is, in fact, echoed in the structure of the act itself. The act consists of four parts: the first, 'Before'; the second, 'The Attacks'; the third, 'The Collapse'; and the last, 'A Year Later'. The titles of the first and last parts suggest that the intensity or severity of the attacks is not just limited to the difficult moments people witnessed during those attacks or the collapse of the buildings. But, this severity is presented by something that starts earlier, as indicated by the title of the first part, and another that extends longer, as indicated by the title of the last one. Also, the titles of the parts in the middle could allude at an 'attack' on the American people's stability which led to the inevitable 'collapse' of their identity.

The most significant implication the first part, entitled 'Before', stresses about the experience of September $11^{\text {th }}$ is that it opened people's eyes on the fallacy of their government's allegations before the attacks. In this part, the writer shows how the attacks could highlight the contrast between the image the government presented about the before-the-attacks American country as the land of opportunities, hope, freedom, and ultimate truth, and the real conditions of that society at that time. This could be the first social political context in which these attacks can be interpreted through. In Cultural Amnesia: Memory, Trauma, and War, Janice Haaken states that it was a mistake to consider the post-traumatic responses of the Americans after the attacks as the result of the attacks alone. He says:

[Such claim] narrowly focuses on concrete dramatic events while neglecting context. The idea that planes can become bombs, that the fabric of daily life may become inflammatory, is not destabilizing as a 
result of the terrorists' attacks alone. The "post-traumatic" responses are intimately related to "pretraumatic" currents in U.S. society (456).

So, Haaken believes that there were some "pretraumatic" events in the American society that lead to the post-traumatic effect that prevailed after the attacks. Haaken's statement can thus explain why people's memories in the first act start even before the attacks. Judith Herman also asserts in Trauma and Recovery: "Reconstructing of the trauma story begins with a review of the patient's life before the trauma and the circumstances that led up to the event" (Herman 126). Hence, the first part introduces the audience to some of the characters as they tell their stories on the morning of the attacks right before their occurrence. Each of these characters can stand for an aspect of the society at the time before the attacks.

There are six characters in part one: Juan, a waiter; Sarah, a mother; Fred, a farmer; Barbara, a stockbroker; nameless, a homeless guy; and Rose, a reporter. Three of them, Juan, Barbara, and the homeless guy, represent three classes in the society at this time: poor immigrants, black women, and homeless people. The other three characters, Sarah, Fred, and Rose, mourn three lost values in this society: hope, human interaction, and truth. The part opens with a slide of the sun rising over Manhattan. A new rise for the sun symbolizes a new hope. This hope was what the first character, Juan Rodrigez, had to the moment right before the attacks. Juan was a Hispanic in his 20s who worked for a restaurant on top of WTC. All he aimed at by working there was getting money. He wanted to save money to be the first member of his family to join college. For Hispanic New Yorkers, as well as for many poor minorities in the American society, it was not such a comfortable life to live; not many of them were able to go to college or, even worse, earn their living. Juan says:

I was saving for college. I would have been the first one in my family to go to college. I wasn't planning on being a waiter all my life. Not a chance I was getting that degree so I could go into real estate - that's where the big bucks really live. (Dumas, act I, part 1,4).

Juan's character is the first sign of the fallacy of the American dream that always asserted that this country is the land of opportunities. According to a statistic published in March 2000 by the U.S. Census Bureau, 22.8 percent of Hispanicsincluding families, female, elderly, children- were living below the poverty level in 1999 compared with 7.7 percent of non-Hispanic(Smith and Smith 6). So, becoming lost when confronted with poverty and severe conditions, the alleged opportunities offered by the American country were among the first things the attacks opened people's eyes on.

Another example of injustice is Barbara who knew that the only way to make it in this world was to depend on one's self. She remembers being one of few women, one of three blacks, and the only black woman in her firm to hold a seat on the Stock Exchange. In spite of all the claims about the disappearance of racism in the American society in the $21^{\text {st }}$ century, Barbara seemed to suffer a lot for being 
first, a woman, and second, a black. It was not an easy success to earn; she had to exert a lot of effort and hard work. Barbara says:

I was one of the few women, one of three blacks and the only black women in my firm to hold a seat on the Stock Exchange. And I didn't get it by sitting on my butt or making friends or holding hands. Nobody helped me. Nobody helps anybody in this business. I earned it, the old fashioned way, by hard work (Dumas, act I, part 1, 5).

Racism, which the blacks suffered long from and which the American society alleged its passing over, is now so powerfully present with what Barbara's character reveals. In fact, one of September $11^{\text {th }}$ implications is said to be the awakening of old traumas such as slavery or racism. However, the play asserts that the attacks proved that racism was never an old story to be told in the American society. It will always be a renewable one. A 2014 article by the European Journal of English Language and Literature Studies asserts the continuation of discrimination to the $21^{\text {st }}$ century. According to this article which is entitled "African Americans and Workplace Discrimination," and which cites from a wide range of studies and statistics conducted in the 1990s and 2000s:

African American women continue to suffer from racial attitudes at work place. Around $77 \%$ of African American nurses in three different nursing homes in Arkansas [for instance] reported extreme discriminatory behavior on part of patients and management. In white collar jobs, African Americans face exclusion from informal social networks, assumptions of incompetence from White co-workers, clients, supervisors, and face many forms of racial bias (qtd. in Fernandes and Alsaeed 63).

Racism was not also the only drawback of the American society at the time right before the attacks.

From down in the tunnels under WTC with a homeless guy to up in the sky with reporter Rose, the slide now brings a chopper that is supposed to carry the traffic reporter Rose Warren, the last character that appears in this part. Rose is the first one to see the planes approaching the buildings and crashing into them from her chopper. Being a TV journalist, Rose can represent media in this play. The slides shift from down in the tunnels to up in the sky- especially after uncovering all these miserable real images of the society- because media has always manipulated people by convincing them that everything was fine and that their country was on top of the world though deep down it was not. So, the attacks could reveal how untrue such claims were and, thus, could undermine the credibility and effect of media as a tool in the government's hand. According to Noam Chomsky, "the true role of the media, far from its stated and illusory democratic purpose, is in reality a tool of the elite interests to expand corporate power" (Miller 4). He says that media supports "established power" and is "responsive to the needs of government and major power groups" (qtd. in Miller 5). 
The second part of act I shows how the attacks affected the Americans' sense of normality as well as that of identity. As Don DeLillo describes $9 / 11$, it is an event that "changed the grain of the most routine moment" and as Laub admits, in an essay published in 2003, "normality abruptly ceased. Life as we have known it stopped" (qtd. in Bond 23). Barbara tells the audience that she thought the best thing she could do at that time was to return back to the building believing she could help do anything, maybe save something or somebody. But, she could not do anything because as she was returning to WTC, it was collapsing. Like those of the rest of the characters in this part, Barbara's story asserts that her reactions were very stable and reasonable. Barbara says: "I made my way from the stock exchange back toward our offices at the World Trade Center. I don't know why. I thought maybe I could help, maybe save something, save somebody" (Dumas, act I, part 2, 10).

Also, the third part, the collapse, could represent the collapse of the American identity. One of the characters, Anthony, says: "It was the first time we had seen the Manhattan skyline without the Twin Towers. It looked wounded, like a mouth missing its teeth" (Dumas, act I, part 3, 12). Barbara, too, thought her country was so strong that nothing as such could happen to it. She says, "This is America, this can't be happening in America" (Dumas, act I, part 3,12). This was what most Americans felt after their collapse. That was also another sign of immune identity that became not so anymore. Keniston and Quinn reflect about the value of these buildings. They admit:

As two of the tallest buildings in the world, the towers also stood for American power and commerce, and for capitalism more generally. After their destruction on September 11, $2001[\ldots]$ the material reality or "fact" of the destruction of the towers has itself been overwhelming (1).

A year after the attacks, characters seem more different as they suffer from PTSD. For instance, nurse Daisy tells the audience that she decided never to go to 'ground zero', the place of WTC after the attacks. She explains why she did not do so:

But, I haven't been to Ground Zero. I figure when I washed the grime from that firefighters scarred and bleeding hands, when I wiped the dust from the face of that crying child, and as I struggle daily to thaw my hardened heart, Ground Zero has come to me. When I breathed in the dust from the essence of three thousand of my lost countrymen I became Ground Zero (Dumas, act I, part 4, 13).

One of the writer's interesting techniques in this act is its non-linear plot or the fragmented way characters' stories are presented through. According to Balaev, authors usually employ a "nonlinear plot or disruptive temporal sequences to emphasize mental confusion, chaos, or contemplation as a response to the experience" (Balaev Trends in Literary Trauma Theory 24). In fact, the technique followed in this act meets some defining features of the traumatic memory referred to by Herman in Trauma and Recovery. Herman says: "Traumatic memories lack 
verbal narrative [...] they are encoded in the form of vivid sensations and images" (27). She also adds that they cause "fragmentary sensations" (28) and appear as a "photographic negative" or "as a series of still snapshots or a silent movie" (125). In this sense, the writer of this play- who is focusing people's memories a year after the attacks in this act- introduces them in a way that matches these very characteristics of the traumatic memories.

First, these stories come in the form of snapshots that focus certain moments of the characters' lives while excluding others with nothing direct to connect them. Accompanied only by the transitional slides, these stories move the audience backward and forward in time and place in a fragmented manner with every new story that is being told. The use of slides itself suits the idea that the writer is dealing with certain memories because people usually use slides to store or register their most significant moments; what remains on a slide is what matters the most and what stays the longest. Besides, as the act's setting itself suggests with the bare stage that indicates no time or place, these memories can interrupt consciousness and appear at any moment regardless of any place or time just as the traumatic memories can do (Herman 125). In fact, the writer's technique in this act compels us to admit that trauma is not only presented as a theme but it is also a technique followed by the writer. Mitchum Huehls refers to how "the trauma of 9/11 becomes a distinctively textual trauma, enacted and also resolved through practices that exceed both the conventionally chronological and the conventionally literary" (43).

Charles Dumas spent six years before he decided to add a second act to his play. In fact, this six-year period has its significance to the representation of September $11^{\text {th }}$ as a traumatic experience. This time dispersal calls upon the mind Caruth's idea of "the belated return of the traumatic event" that was based on Freud's earlier concept of Nachträglichkeit or "latency" or "belatedness" which meant an event can be forgotten over time but then returns in symptomatic compulsive way (Huehls 42). Both Caruth and Freud stressed the idea that the event becomes forgotten or dissociated over this period of time before it imposes itself again on the survivor, and Caruth further established her theory of trans-historical or intergenerational trauma upon this idea (Balaev Trends in Literary Trauma Theory par. 8). The element of belatedness is present in Dumas' play as suggested by the six-year dispersal between the two acts that one can justify the belated composition of the second act in its light. 


\section{Conclusion:}

The paper examined the possibility of representing and claiming a traumatic experience in a literary work. To oppose the common belief of the unrepresentability of traumatic events raised by the classic model of literary trauma theory, it selected the traumatic experience of $9 / 11^{\text {th }}$ attacks and traced it in Charles Dumas' $9 / 11-A$ Day in the Life of A People. Arguing in line with the pluralistic model of literary trauma theory that tried to open new avenues for representing a traumatic experience, this paper suggested certain social-political contexts that allowed for claiming and understanding the traumatic experiences presented in these plays. The analysis of the play discussed in this paper has shown how a traumatic experience could be represented and claimed.

A traumatic experience is not necessary bond to certain situations or may yield into few outcomes; there could be other factors that help shape the aspects of some experiences. These factors may be prior to the experience or following it. In the experience of $9 / 11^{\text {th }}$, they were the false promises of a better society that ensures chances of progress for everyone. However, these attacks revealed that this society was full of ills, including poverty, homelessness, and lack of opportunities, which were all covered up through media. Even worse, the politicization of these attacks for certain aims helped divide the society even years after them creating an entire traumatized society and caused the change in the attitudes of the characters or survivors left behind them. Unfortunately, most of these survivors were fragile ones whose actions were the outcome of these realizations besides being affected by the symptoms of PTSD that characterizes a trauma survivor, such as being haunted by the memories of that day, suffering double-consciousness, showing violent behaviors, and having a deep sense of guilt and confusion. All such facts were asserted by the revelation that most of the survivors of $9 / 11^{\text {th }}$ were not directly exposed to the attacks or were not even in places close to WTC.

Not only did this play reflect this traumatic experience as a theme but also as a technique that suited the time period at which each of its two acts was presented. In act one - written only a year after the attacks, the writer depended on fragmentation and presented characters stories in an unconnected way accompanied only by slides of the attacks. The stage or the act's setting referred to no time or place. All such techniques echoed the characteristics of traumatic memories. In act two - introduced six years after the first one, characters interacted more and used a more conversational language than did the first one. This act had a developing action on a stage that had different scenes and settings. Such different techniques reflected but the traumatic nature of the attacks of $9 / 11^{\text {th }}$. They have also reflected a deeper understanding of how they changed people's actions and attitudes even seven years after their occurrence. 


\section{Bibliography}

Alfano, Sean. "War Casualties Pass 9/11 Death Toll." CBS News Us. 22

Sept. 2006. CBS News. Web. 8 Mar. 2010.

http://www.cbsnews.com/stories/2006/09/22/terror/main2035427.shtml

Balaev, Michelle. "Trends in Literary Trauma Theory." Mosaic

(Winnipeg) 41.2 (June,2008): 149(18). General OneFile. Gale.

Bibliotheca Alexandrina. 6 Oct. 2008.

http://find.galegroup.com/itx/stat.do?prodld=ITOF

---, Ed. Contemporary Approaches in Literary Trauma Theory. New York: Palgrave Macmillan, 2014. Print.

"Bin Laden claims responsibility for 9/11." CBC News. 29 Oct. 2004.cbc.ca.

Web. 8Mar. 2010.

http://www.cbc.ca/world/story/2004/10/29/binladen_message041029 html

Bond, Lucy. Frames of Memory after 9/11: Culture, Criticism, Politics, and Law. Palgrave Macmillan, 2015. Print.

Caruth, Cathy. Unclaimed Experience: Trauma, Narrative, and History. Baltimore: The Johns Hopkins University Press, 1996. Print.

Collins, Catherine Ann and Jean Ellen Clark. "Addressing the Unspeakable.” Speakingthe Unspeakable. Intro., pp. ix-xxix. Inter Disciplinary Press. Oxford: United Kingdom, 2013.

Dumas, Charles. 9/11 - A Day in the Life of A People. No. 516 Pennsylvania: Atherton, State College. Draft sent via E-mail. 16 Feb. 2010.

Elser, Amanda. "A Play To Explore Lives Affected By 9/11." The Daily Collegian Online. 5 Sept. 2008. collegia.psu.edu. Web. 8 Mar. 2010. http://www.collegian.psu.edu/archive/2008/09/05/play_to_explore_lives_aff ected.aspx

Fernandes, Lilly and Nora Hadi Q Alsaeed. "African Americans and Workplace Discrimination.” European Journal of English Language and Literature Studies,Vol.2, No.2, pp. 56-76. June 2014. PDF. European Centre for Research Training and Development UK. www.eajournals.org

Haaken, Janice. "Cultural Amnesia: Memory, Trauma, and War." Gender and Cultural Memory. Vol. 28, No. 1, (Autumn, 2002), pp. 455-457. The University of Chicago Press. PDF. 29/01/2010. http://www.jstor.org/stable/3175727 
Herman, Judith Lewis. Trauma and Recovery: The Aftermath of Violencefrom Domestic Abuse to Political Terror. New York: Basic Books, 1992. Print.

Huehls, Mitchum. "Foer, Spiegelman, and 9/11's Timely Traumas." Keniston and Quinn. pp. 42-58.

Keniston, Ann and Jeann Follansbee Quinn. Eds. "Representing 9/11: Literature and Resistance." Literature after 9/11. New York: Routledge, 2008, pp. 1-15.

Miller, David, Ed. Tell me Lies. Introduction. London: Pluto Press, 2004, pp. $1-13$.

Otten, Michael. "How We Remember: Our Lives Since 9/11." Time Us. Time Us. 8 Sept. 2006. Time.com. Web. 7 Mar. 2010. http://www.time.com/time/nation/article/0,8599,1533178,00.html

Smith, Annetta C. and Demise Smith. "Emergency and Transitional Shelter Population: 2000." Census 2000 Special Reports. U.S. Department of Commerce Economics and Statistics Administration U.S. Census Bureau, 2001.

Versluys, Kristiaan.“Art Spiegelman's In the Shadow of No Towers: 9/11 and the Representation of Trauma." Modern Fiction Studies 52, No. 4, 2006, pp.980-1003.

Vickroy, Laurie. "Voices of Survivors in Contemporary Fiction."

Contemporary Approaches in Literary Trauma Theory. Balaev, pp. 130151.

Wald, Christina. Hysteria, Trauma and Melancholia. Performative Maladies In Contemporary Anglophone Drama. Houndmills, Basingstoke: Palgrave Macmillan, 2007. Print.

Walker, Janet. "The Traumatic Paradox: Autobiographical documentary and the psychology of memory." Contested Pasts: The politics of Memory. Eds. Katherine Hodgkin and Susannah Radstone. New York: Routledge, 2003, pp. 103-115.

Wiley-Blackwell. "Emotional impact of 9/11 attacks seen in brain's response to negative visual images." ScienceDaily, 10 Sep. 2011. Web. 12 Aug. 2015. www.sciencedaily.com/releases/2011/09/1 10909074915.htm 


\section{موجز}

يهدف هذه البحث إلى استكثاف كيف يمكن أن يقوم عمل أدبى معين بتمثيل إحدى التجارب المؤلمة

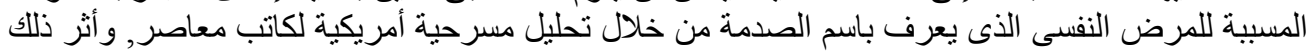

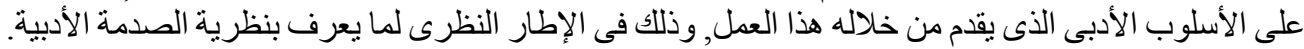

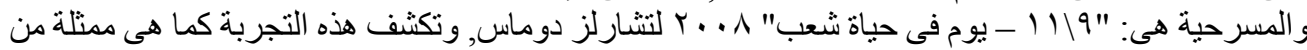

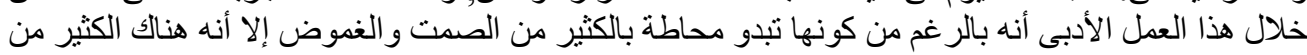

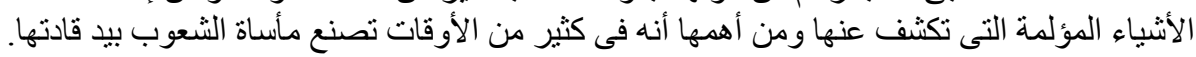

يتتاول البحث من خلال هذه المسرحية تجربة الحادى عشر من سبتمبر و أثرها على العائ العديد من الأفر اد

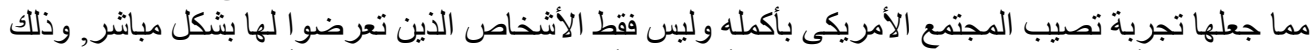

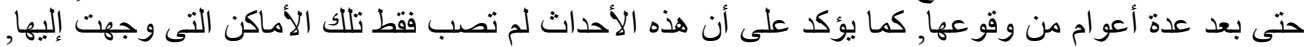

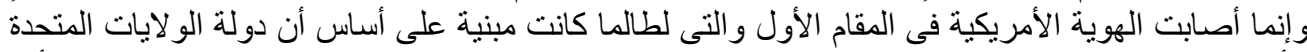

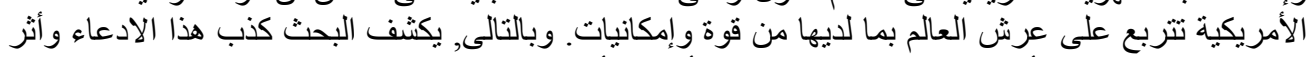

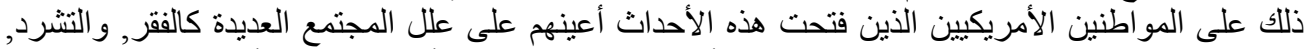

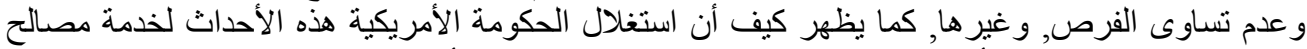

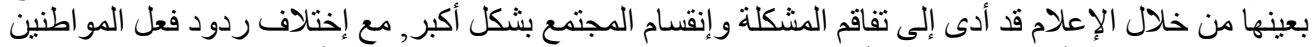

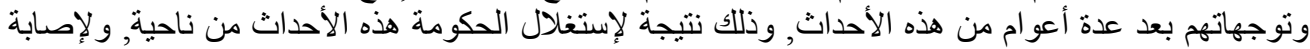

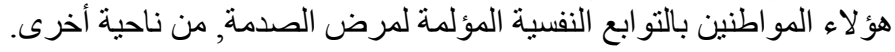

